\title{
Kewirausahaan Sosial dalam Pemberdayaan Ekonomi Umat
}

\section{Mandala Faldini}

STAIN Syaikh Abdurrahman Siddik Bangka Belitung, Indonesia mandalafaldini@gmail.com

\begin{abstract}
Social entrepreneur is a branch of entrepreneur. Solutions of social problems who implementated is a social entrepreneur. A social entrepreneur be required a person who can read a social problem, design a social solution and mobilize the idea in order to implemented. Entrepreneur with social motivation, makes a lot of impact. Social impact of entrepreneur is fullfilment of needs, serve alternative unique product with low cost and provide solutions of goverment problems. Indonesia as a country with muslims as mayority, social entrepreneur is a needs for people economy. Social entrepreneur can be solution of economic gap or disparities in Indonesia.
\end{abstract}

Keywords; social, entrepreneurship, moslem, economy 


\section{A. Perspektif Kewirausahaan}

Wirausaha berasal dari dua kata, yaitu wira dan usaha. Wira secara etimologi berasal dari bahasa Sangiang dan juga bahasa Sanskerta yang berarti berani. Usaha menurut Kamus Besar Bahasa Indonesia (KBBI) adalah kegiatan dengan mengerahkan tenaga, pikiran, atau badan untuk mencapai suatu maksud; pekerjaan (perbuatan, prakarsa, ikhtiar, daya upaya) untuk mencapai sesuatu. Wirausaha juga sering disebut dengan istilah wiraswasta. Swasta berasal dari dua kata, yakni 'swa' dan 'sta'. Swa artinya sendiri, dan sta, berarti berdiri. Jadi, swasta bisa dimaknai berdiri di atas kekuatan sendiri ${ }^{1}$. Wirausahawan adalah orang yang berjiwa berani mengambil risiko untuk membuka usaha dalam berbagai kesempatan. ${ }^{2}$ Wirausaha atau wiraswasta adalah kegiatan berani mengambil risiko dengan mengerahkan segala daya dan upaya dalam mencapai tujuan baik dilakukan individu maupun kelompok secara mandiri.

Seorang wirausaha harus memiliki jiwa berani atau keberanian. Sebagai orang yang berani, seorang wirausahawan harus memiliki hati yang mantap dan rasa percaya diri yang besar. Hati yang mantap memberikan intuisi dalam membaca peluang dan ancaman. Rasa percaya diri memberikan keyakinan dalam membaca kekuatan dan kelemahan. Dunia usaha adalah dunia yang penuh dengan risiko. Risiko di dalam dunia usaha adalah sesuatu yang tidak bisa dihindarkan. Wirausahawan berani mengambil risiko karena mampu melakukan manajemen risiko. Manajemen risiko merupakan berbagai cara penanggulangan risiko. ${ }^{3}$ Seorang wirausaha pun harus mampu mengupayakan seluruh tenaga dan pikiran dalam melaksanan rencana-rencana dalam mencapai tujuan-tujuan yang telah yang telah ditetapkan.

Wirausaha tidak didefinisikan dari modal aset ataupun omzetnya. Berapapun jumlah aset atau omzet, tetapi bila dilakukan secara mandiri dalam menjalankan usahanya, kegiatan tersebut dikatakan wirausaha. Menurut Undang-Undang Nomor 20 Tahun 2008 (UU No. 20 Thn. 2008) tentang Usaha Mikro, Kecil, dan Menengah (UMKM), usaha UMKM dibagi ke dalam empat kriteria seperti tabel di bawah ini:

\footnotetext{
${ }^{1}$ Wasty Soemanto, Sekuncup Ide Operasional Pendidikan Wiraswasta (Jakarta: Bina Aksara, 1984), p. 43.

${ }^{2}$ Kasmir, Kewirausahaa-n (Jakarta: PT Raja Grafindo Persada, 2006), p. 19.

${ }^{3}$ Djojosoedarso, Prinsip-Prinsip Manajemen Risiko dan Asuransi (Jakarta: Salemba Empat, 2003), p. 2.
} 
Tabel 1. Kriteria Usaha

\begin{tabular}{|c|l|l|l|}
\hline \multirow{2}{*}{ No. } & \multirow{2}{*}{ Uraian } & \multicolumn{1}{|c|}{ Kriteria } \\
\cline { 3 - 4 } & & \multicolumn{1}{|c|}{ Aset } & \multicolumn{1}{c|}{ Omzet } \\
\hline 1. & Usaha Mikro & Paling Maksimal Rp 50.000.000,- & Paling Maksimal Rp 300.000.000,- \\
\hline 2. & Usaha Kecil & $\begin{array}{l}\text { Rp 50.000.000,- sampai dengan } \\
\text { Rp 500.000.000,- }\end{array}$ & $\begin{array}{l}\text { Rp 300.000.000,- sampai dengan } \\
\text { Rp 2.500.000.000,- }\end{array}$ \\
\hline 3. & Usaha & $\begin{array}{l}\text { Rp 500.000.000,- sampai dengan } \\
\text { Rp 10.000.000.000,- }\end{array}$ & $\begin{array}{l}\text { Rp 2.500.000.000,- sampai dengan } \\
\text { Rp 50.000.000.000,- }\end{array}$ \\
\hline 4. & Usanengah Besar & $\begin{array}{l}\text { Paling Minimal Rp } \\
10.000 .000 .000,-\end{array}$ & $\begin{array}{l}\text { Paling Minimal Rp } \\
50.000 .000 .000,-\end{array}$ \\
\hline
\end{tabular}

Sesuai dengan perkembangan zaman, pengertian wirausaha juga mengalami perkembangan. Berdasarkan kategori orientasi usaha, wirausaha juga dapat dibagi ke dalam tiga kategori, yaitu:

1. Technopreneur (Wirausaha Berbasis Teknologi)

Technopreneur adalah wirausahawan yang menjalankan usaha menggunakan media teknologi sebagai sumberdaya utamanya. Contoh:

2. Ecopreneur (Wirausaha Ramah Lingkungan)

Ecopreneur adalah wirausaha yang menjalankan usaha yang ramah lingkungan dan mengutamakan keuntungan kepada lingkungan.

3. Sociopreneur (Wirausaha Sosial)

Sociopreneur adalah wirausaha yang menjalankan usaha sebagai solusi atas masalah sosial di masyarakat.

\section{B. Kewirusahaan Sosial}

Pembahasan isu sosial pada saat ini merupakan pembahasan yang pasti banyak menuai pro dan kontra, apalagi terkait dengan kewirausahaan. Sosial terkait dengan kepentingan masyarakat umum, sedangkan kewirausahaan pada saat ini lebih identik dengan keuntungan pemilik usaha pribadi. Menurut Dees, kewirausahaan sosial adalah salah satu dari spesies didalam genus kewirausahaan. ${ }^{4}$ Kewirausahaan sosial menjadi fenomena yang sangat menarik saat ini karena perbedaan-perbedaannya dengan

\footnotetext{
${ }^{4}$ Sebagaimana dikutip Peter A.D., M.Tina D., Margaret Matear, 'Social Entrepreneurship: Why We Don't Need a New Theory and How We Move Forward from Here', Articles of Academy of Management Perspectives, August 2010, p. 38.
} 
wirausaha tradisional yang hanya fokus terhadap keuntungan materi dan kepuasan pelanggan, serta signifikansinya terhadap kehidupan masyarakat. ${ }^{5}$

Walaupun istilah kewirausahaan sosial bukan sebagai istilah yang populer, tetapi ide dari kewirausahaan sosial ini merupakan rancangan gagasan lama. Pada praktiknya, hal ini sudah banyak dilakukan sejak awal zaman manusia saling berinteraksi. Hal tersebut dapat dibuktikan dari literatur-literatur agama yang ada saat ini. Sebagai contoh Firman Allah SWT Q.S An-nisaa' ayat 29, (Hai orang-orang yang beriman! Janganlah kamu makan harta sesamamu dengan jalan yang batil). Artinya, jalan yang haram menurut agama seperti riba dan gasab/merampas (kecuali dengan jalan) atau terjadi (secara perniagaan) menurut suatu qiraat ${ }^{6}$ dengan baris di atas sedangkan maksudnya ialah hendaklah harta tersebut harta perniagaan yang berlaku (dengan suka sama suka di antara kamu) berdasar kerelaan hati masing-masing, maka bolehlah kamu memakannya. (Dan janganlah kamu membunuh dirimu), artinya dengan melakukan hal-hal yang menyebabkan kecelakaannya bagaimana pun juga cara dan gejalanya baik di dunia dan di akhirat. (Sesungguhnya Allah Maha Penyayang kepadamu), sehingga dilarang-Nya kamu berbuat demikian). ${ }^{6}$

Dari tafsir di atas dijelaskan bahwa ketika memanfaatkan harta, harta yang didapatkan harus melalui cara-cara yang benar. Cara yang benar yang dimaksud adalah melalui perniagaan, bukan melalui transaksi riba atau dengan cara merampas harta orang lain. Dalam perniagaan pun ada aturan-aturannya. Perniagaan harus dilakukan dengan dasar saling menerima, tanpa ada salah satu pihak yang merasa dirugikan.

Meskipun kewirausahaan sosial ini merupakan isu lama yang sudah ada dan dijalankan oleh masyarakat, tetapi pada saat ini istilah kewirausahaan dapat dikatakan sebagai istilah yang tidak lazim. Hal ini disebabkan karena sistem perekonomian yang saat ini sangat jauh dari sistem sosial. Sistem sosial terus mengalami kemunduran, terdepresiasi oleh sistem kapitalis. Pengertian sistem ekonomi kapitalis adalah suatu sistem yang memberikan kebebasan yang cukup besar bagi pelaku-pelaku ekonomi untuk melakukan kegiatan yang terbaik bagi kepentingan individual atas beberapa sumber daya ekonomi atau faktor-faktor produksi. Sistem ekonomi dibanyak negara saat

\footnotetext{
${ }^{5}$ Hadi Utomo, 'Menumbuhkan Minat Kewirausahaan Sosial', Jurnal STIE AMA Salatiga, vol. 7, no. 14, (2014), p. 1.

${ }^{6}$ Imam Jalaluddin Al-Mahally \& Imam Jalaluddin As-Suyutti, Tafsir Jalalain Berikut Asbab An-nujulnya, Jilid I (Bandung,: Sinar Baru, 1990), p. 52.
} 
ini menggunakan sistem kapitalis. ${ }^{7}$ Sistem kapitalis dinilai Marx mewarisi daya selfdestruction, suatu daya dari dalam yang akan membawa kehancuran bagi sistem perekonomian liberal itu sendiri. ${ }^{8}$

Dengan pesatnya perkembangan dunia dibidang sosial, usaha dan pendidikan, kemudian banyak literatur-literatur yang membahas tentang kewirausahaan sosial. Secara tidak langsung, literatur-literatur yang ada kemudian memotivasi para pelaku wirausaha untuk membuka pola pikir dan mengembalikan pemahaman banyak orang terkait kewirausahaan. Alvord, Brown, dan Letts mengatakan bahwa kewirusahaan sosial menciptakan solusi-solusi inovatif terhadap masalah-masalah sosial terkini dan memobilisasi ide-ide, kemampuan, dan pengaturan sosial yang dibutuhkan untuk transformasi sosial yang berkelanjutan. ${ }^{9}$ Hal ini berarti seorang wirausahawan sosial harus memiliki kecerdasan mengidentifikasi masalah, ketepatan memberikan solusi terkait masalah serta keahlian dalam hal implementasi agar gagasan usaha terus memberikan dampak sosial positif kepada masyarakat.

Gagasan tanpa implementasi tidak akan memberikan dampak. Akan tetapi, implementasi merupakan seni yang tidak ada batasan ketika sudah mulai dikerjakan, sehingga visi dari usahawan sosial harus kuat dan jelas agar gagasan bermanfaat. Dalam pelaksanaan pengimplementasian gagasan tersebut, pastinya kita akan mendapatkan banyak sekali permasalahan. Seorang jiwa wirausaha sosial harus mempunyai kemampuan pengelolaan risiko agar dapat menuntaskan apa yang menjadi idenya tersebut. ${ }^{10}$ Tidak ada usaha yang tidak ada risiko, walaupun risiko itu akan menjadi masalah. Wirausaha sosial melihat masalah sebagai peluang untuk membentuk sebuah model bisnis baru yang bermanfaat bagi pemberdayaan masyarakat sekitar. ${ }^{11}$

Dengan meningkatnya interaksi sosial antar masyarakat seperti saat ini, seharusnya kewirausahaan sosial semakin mudah berkembang. Akan tetapi, motivasi keuntungan dari sistem kapitalis perlahan harus segera diubah. Hasil yang ingin dicapai bukan keuntungan materi atau kepuasan pelanggan, melainkan bagaimana gagasan yang

\footnotetext{
${ }^{7}$ Agustiati, 'Sistem Ekonomi Kapitalisme', Jurnal Academica Universitas Tadulako, vol. 1 no. 2 (2009), p. 154. ${ }^{8}$ Hasbiullah, 'Krisis Ekonomi Global dan Kegagalan Kapitalisme', Jurnal Ilmu Ekonomi Studi Pembangunan, vol. 1 no. 2 (2009), p. 123.

${ }^{9}$ Alvord, S.H., Brown, L.D., \& Letts, C.W., 'Social Entrepreneurship and Societal Transformation', Journal of Apllied Behavioral Science, vol. 40 no. 3 (2004), p. 262.

${ }^{10}$ Braun, Karen, 'Social Entrepreneurship: Perspectives on an Academic Discipline', Theory in Action, vol. 2, no. 2, (2009), p. 34

${ }^{11}$ Ibid., p. 55.
} 
diajukan dapat memberikan dampak baik bagi masyarakat. ${ }^{12}$ Ketika usaha telah memberikan dampak baik bagi masyarakat, usaha akan bisa bertahan dan terus tumbuh berkembang. Kemudian setelah usaha terus berkembang, para konsumen atau pelanggan akan merasa puas. Saat pelanggan atau konsumen merasa puas, pelanggan akan loyal.

Untuk menjadikan seseorang sebagai usahawan sosial yang handal, dibutuhkan ilmu dan pengalaman. Ilmu akan memberikan fondasi, sedangkan pengalaman akan melapisi fondasi tersebut agar lebih kuat. Kewirausahaan sosial adalah disipilin ilmu yang menggabungkan antara kecerdasan berbisnis, inovasi, dan tekad untuk maju ke depan. ${ }^{13} \mathrm{Hal}$ ini akan membuat suatu sistem yang sempurna, dimana kemampuan mampu atau bahkan melebihi dari kebutuhan, keinginan dan harapan transaksi para pelanggan atau konsumen. Customer satisfaction is the state in which customer needs, wants and expectation the transaction cycle was met or exceeded, resulting in repurchasing and continuity loyalty. ${ }^{14}$ Artinya kepuasan pelanggan merupakan tingkat dimana kebutuhan, keinginan dan harapan dari pelanggan dapat terpenuhi melalui suatu transaksi, serta dapat mengakibatkan pembelian ulang atau kesetiaan berlanjut. Loyalitas sangat penting karena diharapkan perusahaan akan mendapatkan keuntungan jangka panjang atas hubungan mutualisme yang terjalin dalam kurun waktu tertentu. ${ }^{15}$

\section{Kondisi Ekonomi Umat}

Umat menurut KBBI adalah penganut (pemeluk, pengikut) suatu agama. Sebagai negara mayoritas penduduknya adalah beragama islam, ketika berbicara konteks ekonomi umat, hal tersebut sangat identik dengan ekonomi umat Islam. Membahas tentang ekonomi umat pun konteksnya tidak lepas dari ekonomi umat Islam di Indonesia, karena kondisi ekonomi umat Islam di Indonesia sangat jauh berbeda dengan kondisi ekonomi umat Islam di negara lain.

Indonesia sebagai negara mayoritas Islam, yaitu sebesar 207.176.162 dari total penduduk sebesar 237.641.326 atau $87,18 \%$ penduduknya beragama Islam. ${ }^{16}$ Akan

\footnotetext{
${ }^{12}$ A.B. Susanto, Corporate Social Responsibility, (Jakarta: The Jakarta Consulting Group, 2007), p. 54.

${ }^{13}$ Band, W.A., Creating Value of Customer: Designing and Implementation a Total Corporate Strategy (Canada: John Walley and Son Inc, 1991), p. 191.

${ }^{14}$ Vasudha Vasakaria, 'A Study on Social Entrepreneurship and the Characteristics of Social Entrepreneur', the Icfaian Journal of Management Research, vol. vii, no. 4 (2008), p. 35.

15 Meyta Pritandhari, 'Analisis Faktor-Faktor yang Mempengaruhi Loyalitas Pelanggan dan Dampaknya terhadap Keunggulan Bersaing (Studi pada BMT Amanah Ummah Sukoharjo)', Jurnal Pendidikan Ekonomi UM Metro, vol. 3 no. 1 (2015), p. 51.

16 Sensus kependudukan tahun 2010 yang dilakukan oleh Badan Pusat Statistik (BPS)
} 
tetapi dibidang ekonomi, umat Islam di Indonesia bukan menjadi mayoritas dalam penguasaan aset. Sektor perbankan dan modal saat ini dikuasai oleh bank-bank dan perusahaan-perusahaan yang dipimpin oleh orang non-Islam. Aset keuangan bank syari'ah di Indonesia hanya berjumlah 3,28\% dibandingkan dengan total aset keuangan bank nasional. ${ }^{17}$ Dari 50 orang terkaya di Indonesia, hanya ada delapan orang yang beragama Islam. ${ }^{18}$

Gini Ratio adalah indikator yang menunjukkan tingkat ketimpangan pendapatan secara menyeluruh. Badan Pusat Statistik (BPS) mengumumkan pada bulan Maret 2017 bahwa tingkat Gini Ratio Indonesia adalah sebesar 0,393\%. Angka ini artinya terjadi kesenjangan yang cukup besar diantara penduduk di Indonesia dimana mayoritasnya adalah umat Islam. Kesenjangan ekonomi ini menunjukkan bahwa penguasaan ekonomi dalam hal aset umat Islam di Indonesia sangat tidak berdaya.

Ketidakberdayaan umat Islam dalam penguasaan aset ini disebabkan oleh banyak faktor. Di zaman kapitalisme seperti ini, umat Islam memliki keterbatasan dalam mengakses modal, baik secara mandiri maupun melalui jasa keuangan perbankan dan non-bank. Sumber modal maupun sistem sumber modal dikuasai oleh non-Islam dengan solid. Salah satu faktor lainnya adalah rendahnya tingkat pendidikan dan penguasaan ilmu teknologi di era digital saat ini. Para usahawan Islam tradisional kalah bersaing dengan usahawan non-muslim yang sudah berinovasi dengan dunia teknologi.

\section{Pemberdayaan Ekonomi Umat}

Pemberdayaan adalah suatu proses berkesinambungan perubahan nasib, tumbuh dan berkembang, serta perbaikan taraf kehidupan masyarakat. Pemberdayaan merunjuk pada kemampuan orang khususnya kelompok rentan dan lemah, sehingga mereka memiliki kekuatan atau kemampuan dalam (a) memenuhi kebutuhan dasarnya sehingga mereka memiliki kebebasan (freedom), dalam arti bukan saja bebas mengemukakan pendapat, melainkan bebas dari kelaparan, bebas dari kebodohan, dan bebas dari kesakitan, (b) menjangkau sumber-sumber produktif yang memungkinkan mereka dapat meningkatkan pendapatanya dan memperoleh barang-barang dan jasa-jasa yang mereka

\footnotetext{
17 Statistik Perbankan Indonesia (SPI) Vol: 9 No. 2 Bulan Januari Tahun 2011 yang diumumkan oleh Bank Indonesia.

${ }^{18}$ Forbes di website https://www.forbes.com/indonesia-billionaires/list/\#tab:overall
} 
perlukan, (c) berpartisipasi dalam proses pembangunan dan keputusan-keputusan yang mempengaruhi kehidupan mereka. ${ }^{19}$ Proses pemberdayaan masyarakat terdiri dari lima tahap:

1. Menghadirkan kembali pengalaman yang dapat memberdaya guna dan tidak memberdayakan.

2. Mendiskusikan alasan mengapa terjadi pemberdayaan dan tidak memberdayakan.

3. Mengidentifikasi masalah.

4. Mengidentifikasi basis daya yang bermakna.

5. Mengembangkan rencana-rencana aksi dan pengimplementasian. ${ }^{20}$

Memberdayakan masyarakat berarti meningkatkan kemampuan masyarakat dengan cara mengembangkan dan mendinamisasi potensi-potensi masyarakat dalam rangka meningkatkan harkat dan martabat seluruh lapisan masyarakat. Dengan kata lain, menjadikan masyarakat mampu dan mandiri dengan menciptakan iklim yang memungkinkan potensi masyarakat berkembang. Pemberdayaan bukan hanya meliputi penguatan anggota individu dan anggota masyarakat, tetapi juga pranata-pranatanya, menanamkan nilai-nilai budaya modern seperti kerja keras, hemat, keterbukaan, dan tanggung jawab adalah bagian pokok dari upaya pemberdayaan. ${ }^{21}$

Konsep pemberdayaan umat adalah reaksi dari kegelisahan atas ketidak berpihakan ekonomi terhadap mayoritas umat di Indonesia. Hal ini terjadi bukan disebabkan karena agamanya, melainkan karena umatnya. Agama Islam pernah mengalami kejayaan disegala bidang, termasuk ekonomi pada zaman Nabi Muhammad SAW serta para sahabat. Ajaran-ajaran agama Islam pun berisi tentang kesejahteraan, meskipun hal-hal duniawi bukan merupakan target utama umat Islam. Banyak ayat AlQur'an yang menyebutkan hal diatas, diantaranya adalah:

1. Dan tiadalah kehidupan dunia ini, selain dari main-main dan senda gurau belaka. Dan sungguh kampung akhirat itu lebih baik bagi orang-orang yang bertakwa. Maka tidakkah kamu memahaminya?22

${ }^{19}$ Edi Suharto, Membangun Masyarakat Memberdayakan rakyat, (Bandung: PT Refika Aditama, 2005), p. 58.

${ }^{20}$ Nanich Machendra dan Agus Ahmad Syafe'I, Pengembangan Masyarakat Islam, (Bandung: Rosdakarya, 2001), p. 25.

21 Sulistiati, Isu-isu Tematik Pembangunan Sosial: Konsepsi dan Strategi (Jakarta: Balai latihan dan pengembangan Sosial Depsos RI, 2004), p. 229.

22 Al-Qur'an, 6:32. 
2. Dan tiadalah kehidupan dunia ini melainkan senda gurau dan main-main. Dan sesungguhnya akhirat itulah yang sebenarnya kehidupan, kalau mereka mengetahui. ${ }^{23}$

3. Sesungguhnya kehidupan dunia hanyalah permainan dan senda gurau. Dan jika kamu beriman serta bertakwa, Allah akan memberikan pahala kepadamu dan Dia tidak akan meminta harta-hartamu. ${ }^{24}$

Ketiga ayat di atas harus dimaknai dengan sangat hati-hati agar tidak terjadi kejatuhan umat Islam. Ayat-ayat tersebut tidak boleh dimaknai secara negatif. Berdasarkan tafsir Kitab Jalalain, ayat pertama adalah perintah agar umat islam menjadi orang yang beriman. Ayat kedua membahas tentang umat agar meninggalkan perkara yang hanya terkait dengan hal-hal duniawi saja. Ayat ketiga maksudnya adalah larangan menyibukkan diri dalam kehidupan dunia. Sebaliknya, ketiga ayat ini apabila dimaknai dengan positif, berwirausaha atau berniaga adalah salah satu anjuran dari ketiga ayat tersebut. Berwirausaha adalah salah satu ibadah atau suatu hal akhirat. Mencari harta dengan cara yang tidak batil bukan hal duniawi.

Allah SWT berfirman, "Hai orang-orang yang beriman, sukakah kalian Aku tunjukkan suatu perniagaan yang dapat menyelamatkan kalian dari azab yang pedih. Yaitu kalian beriman kepada Allah dan Rasul-Nya dan berjihad di jalan Allah dengan harta dan jiwa kalian. Itulah yang lebih baik bagi kalian jika kalian mengetahui."25 Memiliki harta pun ibadah apabila harta tersebut dimanfaatkan untuk kebaikan agama Islam. Dari kalimat-kalimat tersebut, dapat disimpulkan bahwa konsep kewirausahaan sosial adalah salah satu bidang kewirausahaan yang sangat cocok bagi umat Islam sebagai salah satu metode pemberdayaan ekonomi umat.

\section{E. Peran Kewirausahaan Sosial Dalam Pemberdayaan Ekonomi Umat}

Social enterprises-defined simply-are organisations seeking business solutions to social problems. ${ }^{26}$ Kewirausahaan sosial secara sederhana dapat didefinisikan sebagai organisasi pencari solusi-solusi terhadap masalah-masalah sosial. Kewirausahaan sosial ada akibat berhasilnya identifikasi terhadap masalah sosial yang ada pada masyarakat

\footnotetext{
23 Al-Qur'an, 29:64.

${ }^{24}$ Al-Qur'an, 47:36.

25 Alqur'an, 61:10-11

26 Thompson \& Doherty, 'The Diverse World of Social Enterprise: A Collection of Social Enterprise Stories', International Journal of Social Economics, vol. 33, Issue: 5/6 (2006), p. 362.
} 
kemudian disediakan solusinya. Solusi atas masalah sosial yang berhasil diimplementasikan yang menjadi cikal bakal kewirausahaan sosial. Masalah sosial dimasyarakat terkait kewirausahaan sosial pun dapat diketaui dari peluang-peluang, kemudian peluang tersebut harus bisa dibaca dengan tepat agar bisa menjadi gagasan yang baik atas permasalahan sosial yang terjadi.

Wirausahawan sosial adalah orang-orang yang menyadari dimana ada peluang memenuhi kepuasan kebutuhan yang tidak terpenuhi yang mana tanggung jawab negara akan kesejahteraan tidak terpenuhi dan berkumpul bersama sumber daya yang dibutuhkan (umumnya orang, sering juga relawan, uang dan tempat) dan menggunakan hal tersebut untuk membuat perbedaan. ${ }^{27}$ Orang-orang kewirausahaan sosial juga adalah orang-orang yang berbeda, memiliki pola pikir di luar nalar berpikir orang kebanyakan.

Para wirausahawan sosial adalah orang-orang yang memiliki jiwa sosial sangat tinggi dan juga memiliki kemampuan bisnis yang sangat baik. Orang-orang dengan kualitas dan perilaku yang terkait dengan usaha bisnis tetapi beroperasi di dalam komunitas dan lebih memperhatikan terhadap kepedulian dan saling tolong menolong daripada mencari keuntungan materi. ${ }^{28}$ Kewirausahaan sosial adalah tentang pola pikir bisnis sebenarnya semenjak awal manusia saling berinteraksi. Orang yang berjiwa sosial dalam menjalankan bisnis bukan tidak mendapatkan keuntungan materi sama sekal. Bisa jadi keuntungan materi yang didapatkan lebih besar dibandingkan dengan orang yang fokus berbisnis untuk mencari materi. Orang yang memiliki karakter kewirausahaan sosial sangat menyadari bahwa materi atau sesuatu yang terkait dengan kesejahteraan pribadi sangat terkait dengan apa yang dikerjakannya.

Tujuan utama dari pengusaha sosial adalah melayani kebutuhan dasar masyarakat, sementara pengusaha tradisional adalah untuk meraih pasar yang besar kesenjangan dan memperoleh keuntungan, dalam proses bertaraf minimum untuk kepentingan masyarakatnya. ${ }^{29}$ Salah satu tujuan utama wirausaha adalah dalam rangka pemenuhan kebutuhan pokok manusia, tetapi dalam kewirausahaan sosial, sumber daya yang digunakan tidak dipandang sebagai beban atau biaya. Kebutuhan manusia

27 Thompson, Alvy \& Lees, 'Social Entrepreneurship: A New Look At the People and the Potential', International Journal of Management Decision, vol. 38, issue: 5 (2000), p. 328.

${ }^{28}$ Thompson, 'The world of the social entrepreneur', International Journal of Public Sector Management, vol. 15, issue: 5 (2002), p. 413.

${ }^{29}$ Jerry Z. Muller, the Mind and the Market (New York: Alfred A. Knopf, 200), p. 78. 
dipandang sebagai prioritas, tidak bisa diganti dengan produk serupa dengan harga yang lebih murah atau bahkan dengan kualitas yang lebih rendah.

Untuk itu wirausahawan sosial dituntut juga memiliki kelebihan khusus dalam menyediakan dan menyiapkan produk yang ditawarkan sebagai solusi atas masalah sosial yang ada di masyarakat tersebut. Kelebihan khusus tersebut bisa dalam bentuk menghasilkan produk yang inovatif, menciptakan produk yang baru, pemutusan rantai tengkulak, penguasaan teknologi dan kelebihan-kelebihan lainnya. Dengan kata lain, selain memiliki ilmu dan pengalaman, wirausahawan juga harus memiliki gagasan unik, kreatif dan inovatif. Hal ini tentunya sangat bergantung kepada bagaimana isi dari gagasan yang ditawarkan, pada dasarnya agar gagasan serta ide yang kita tawarkan bisa diterima oleh masyarakat kita harus memiliki misi sosial di dalamnya semata-mata hanya untuk membuat masyrakat dapat terbebaskan dari permasalahan yang terjadi. ${ }^{30}$

Dengan jumlah umat Islam yang banyak dan mayoritas, kewirausahaan sosial juga dapat mengurangi jumlah pengangguran dengan menciptakan lapangan pekerjaan dan lapangan usaha. Dengan adanya pekerjaan, secara otomatis pendapatan masyarakat meningkat dan kualitas kehidupan juga jadi baik. Hal ini berakibat terhadap kemampuan daya beli masyarakat yang juga ikut naik, akhirnya produktivitas nasional akan meningkat. Dengan turunnya pengangguran akan juga berdampak ke tingkat pendidikan dan jumlah angka kriminalitas juga akan menurun. Akan tetapi, kewirausahaan sosial juga harus mendapatkan keuntungan, tapi bukan menjadi prioritas utama. Dengan keuntungan tersebut, wirausahawan sosial akan bisa memberikan dampak sosial yang lebih besar dan secara berkesinambungan. Dengan keuntungan, wirausahawan sosial akan mengembangkan usahanya dan membesarkan pemberdayaan ekonomi umat yang lebih luas di wilayah sosial lainnya.

\section{F. Penutup}

Kesimpulannya, kewirausahaan adalah kegiatan sosial, manfaat bagi wirausahawan (kesejahteraan, pengakuan masyarakat, kebanggaan, kebahagiaan dan manfaat lainnya) adalah dampak dari aksi sosial kewirausahaan. Semakin tinggi dampak sosial yang dilakukan oleh kewirausahaan, maka akan berdampak lurus terhadap

\footnotetext{
30 Matin, Roger L. \& Sally Osberg, Social Entrepreneurship: The Case for Definition (San Fransisco: Leland Stanford Jr. University. 2007), p. 12.
} 
Mawa'izh

Jurnal Dakwah dan Pengembangan Sosial Kemanusiaan

Vol. 8, no. 1 (2017), pp. 126-139

manfaat kepada wirausahawan. Begitu juga sebaliknya, wirausaha yang fokus terhadap manfaat wirausahawan secara individu, tidak akan diterima manfaat yang nyata kepada wirausahawan itu sendiri. 


\section{DAFTAR PUSTAKA}

A.B. Susanto, Corporate Social Responsibility. Jakarta: The Jakarta Consulting Group, 2007. Agustiati, Sistem Ekonomi Kapitalisme, Jurnal Academica Universitas Tadulako, Vol. 1 No. 2, 2009.

Al-Mahally, Imam Jalaluddin dan Imam Jalaluddin As-suyutti, Tafsir Jalalain Berikut Asbab An-nujulnya, Jilid I Bandung: Sinar Baru, 1990.

Alvord, S.H., Brown, L.D., \& Letts, C.W., Social Entrepreneurship and Societal Transformation, Journal of Apllied Behavioral Science, Vol. 40 No. 3, 2004.

Band, W.A., Creating Value of Customer: Designing and Implementation a Total Corporate Strategy. Canada: John Walley and Son Inc, 1991.

Bank Indonesia, Statistik Perbankan Indonesia (SPI) Vol: 9 No. 2 Bulan Januari Tahun 2011

Badan Pusat Statistik, Penduduk Menurut Wilayah dan Agama Yang Dianut. http://sp2010.bps.go.id/index.php/site/tabel?tid=321

Braun, Karen. Social Entrepreneurship: Perspectives on an Academic Discipline. Theory in Action, Vol. 2, No. 2, April 2009.

Djojosoedarso, Prinsip-Prinsip Manajemen Risiko dan Asuransi, Jakarta: Salemba Empat, 2003.

Edi Suharto, Membangun Masyarakat Memberdayakan rakyat, Bandung: PT Refika Aditama, 2005.

Forbes, Indonesia's 50 Richest. https:// www.forbes.com/ indonesiabillionaires/ list/ \#tab:overall

Hadi Utomo, Menumbuhkan Minat Kewirausahaan Sosial, Jurnal STIE AMA Salatiga, Vol. 7 No. 14, Desember 2014.

Hasbiullah, Krisis Ekonomi Global dan Kegagalan Kapitalisme, Jurnal Ilmu Ekonomi Studi Pembangunan, Vol. 1 No. 2, Juli-Oktober 2009.

Jerry Z. Muller, The Mind and The Market. New York: Alfred A. Knopf. 2002

Matin, Roger L. \& Sally Osberg, Social Entrepreneurship: The Case for Definition. San Fransisco: Leland Stanford Jr. University. 2007

Kasmir, Kewirausahaan, Jakarta: PT Raja Grafindo Persada, 2006 
Meyta Pritandhari, Analisis Faktor-Faktor yang Mempengaruhi Loyalitas Pelanggan dan Dampaknya terhadap Keunggulan Bersaing (Studi pada BMT Amanah Ummah Sukoharjo). Jurnal Pendidikan Ekonomi UM Metro, Vol. 3 No. 1, Tahun 2015.

Nanich Machendra dan Agus Ahmad Syafe'I, "Pengembangan Masyarakat Islam", (Bandung: Rosdakarya, 2001).

Peter A.D., M.Tina D., Margaret Matear, Social Entrepreneurship: Why We Don't Need A New Theory and How We Move Forward From Here, Articles of Academy of Management Perspectives, August 2010.

Salimudin, Qira'at dalam Kitab Tafsir, Skripsi UIN Sunan Kalijaga, Januari 2016.

Sulistiati, "Isu-isu Tematik Pembangunan Sosial: Konsepsi dan Strategi (Jakarta: Balai latihan dan pengembangan Sosial Depsos RI, 2004)

Thompson, The world of the social entrepreneur", International Journal of Public Sector Management. Vol. 15 Issue: 5. 2002

Thompson, Alvy \& Lees, Social entrepreneurship - a new look at the people and the potential. International Journal of Management Decision, Vol. 38 Issue: 5. 2000

Thompson \& Doherty, The diverse world of social enterprise: A collection of social enterprise stories. International Journal of Social Economics, Vol. 33 Issue: 5/6. 2006

Vasudha Vasakaria. A Study on Social Entrepreneurship and the Characteristics of Social Entrepreneur. The Icfaian Journal of Management Research, Vol. VII, No. 4, 2008. Wasty Soemanto, Sekuncup Ide Operasional Pendidikan Wiraswasta Jakarta: Bina Aksara, 1984. 